\title{
KOMBINASI RSS DAN SBR DALAM TEKNOLOGI PEMBUATAN KARET BANTALAN KAKI UNTUK MEBEL
}

\author{
COMBINATION OF RSS AND SBR IN TECHNOLOGY DEVELOPMENT OF \\ RUBBER STEP FOR FURNITURE
}

\author{
Syamsul Bahri dan Aprillena Tornadez Bondan \\ Balai Riset dan Standardisasi Industri Palembang \\ Jalan Perindustrian II No. 12 Km. 9 Palembang 30152 \\ e-mail: benaprio@gmail.com
}

Diterima: 15 Desember 2017 ; Direvisi: 2 Januari 2018 - 22 Juni 2018; Disetujui: 28 Juni 2018

\begin{abstract}
Abstrak
Penelitian ini bertujuan untuk memperoleh formulasi dalam pembuatan karet bantalan kaki untuk mebel yang mendekati persyaratan teknis SNI 06-7032-2004 untuk Karet Bantalan Kaki (Rubber Step) Sepeda Motor. Dalam penelitian ini dilakukan variasi penggunaan bahan baku karet alam ribbed smoked sheet (RSS) dengan karet sintetis styrene butadiene rubber (SBR). Formulasi kompon karet dengan komposisi karet alam RSS sebanyak 100, 70, 50 dan 30 phr, serta SBR sebanyak 0, 30, 50 dan 70 phr. Pengujian dilakukan terhadap parameter kekerasan/hardness (ASTM D 2240), tegangan putus/tensile strength (ASTM D 412), perpanjangan putus/elongation at break (ASTM D 412), tegangan tarik/modulus 100\% (ASTM D 412), ketahanan sobek/tear resistance (ASTM D 624), ketahanan kikis/abrassion (ASTM D 298) dan pampatan tetap/compression set $25 \%$, dengan 3 (tiga) kali pengulangan pengujian untuk masing-masing parameter. Hasil uji kompon yang terbaik terdapat pada kompon formula III, dimana karet alam RSS yang digunakan sebanyak 50 phr dan SBR sebanyak 50 phr. Hasil pengujian menunjukkan bahwa hasil uji kekerasan sebesar 68 Shore $A$, tegangan putus $120 \mathrm{~kg} / \mathrm{cm}^{2}$, perpanjangan putus $355 \%$, tegangan tarik $100 \%$ yaitu $25 \mathrm{~kg} / \mathrm{cm}^{2}$, ketahanan sobek $33 \mathrm{~kg} / \mathrm{cm}^{2}$, ketahanan kikis $2,4 \mathrm{~mm} / \mathrm{kgm}, \mathrm{dan}$ pampatan tetap $25 \%$ sebesar $23 \%$.
\end{abstract}

Kata kunci : karet bantalan kaki, RSS, SBR, mebel

\begin{abstract}
This research was aimed to formulate the rubber step for furniture that meet its technical specification which approach to SNI 06-7032-2004 for Rubber Step of Motor Vehicle. This research used Ribbed Smokes Sheet (RSS) as natural rubber, combined with Styrene Butadiene Rubber (SBR) as synthetic rubber. The formulation of rubber compound used 100, 70, 50 and $30 \mathrm{phr}$ of RSS, and 0, 30, 50 and 70 phr of SBR. The observed parameters for compounds were hardness (ASTM D 2240), tensile strength (ASTM D 412), elongation at break (ASTM D 412), modulus 310\% (ASTM D 412), tear resistance (ASTM D 624), abrasion (ASTM D 298), and compression set $25 \%$. The result showed that the best compound was formula III (contained 50 phr of RSS and 50 phr of SBR) with the test result for hardness was 68 Shore $A$, tensile strength $120 \mathrm{~kg} / \mathrm{cm}^{2}$, elongation at break $355 \%$, modulus $100 \%$ was 25 $\mathrm{kg} / \mathrm{cm}^{2}$, tear resistance $33 \mathrm{~kg} / \mathrm{cm}^{2}$, abrasion resistance $2,4 \mathrm{~mm}^{3} / \mathrm{kgm}$, and compression set $25 \%$ value was $23 \%$.
\end{abstract}

Keywords : rubber step, RSS, SBR, furniture

\section{PENDAHULUAN}

Penggunaan karet alam dunia menurut Sommer (2009) semakin berkembang, karena sifatnya yang unik, seperti memiliki sifat perpanjangan, kekuatan, daya serap energi dan daya fisik yang tinggi. Selain karet alam, terdapat juga karet sintetis, seperti butadiene rubber (BR), isoprene rubber (IR), styrene-butadiene copolymers (SBR) (White \& Naskar, 2009). Karet sintetis mempunyai sifat yang berbeda dengan karet alam. Material jenis ini juga menghadirkan stabilitas ultraviolet dan oksigen dengan sangat baik (Hassan et al., 2012).

Melihat perkembangan barang jadi karet, saat ini penggunaan karet sintetis memang cukup memegang peranan penting dalam industri seperti industri mebel khususnya karet bantalan kaki. Karet bantalan kaki mebel digunakan sebagai karet kaki meja maupun kursi yang berguna dalam memberikan efek anti geser, menyerap getaran, mengurangi kebisingan dan mencegah terjadinya cacat pada 
permukaan lantai. Dalam pembuatan kompon karet bantalan kaki, semua bahan baku utama (karet alam dan sintetis) dicampurkan secara merata hingga homogen. Selain bahan baku utama, digunakan juga bahan pengisi (filler). Menurut Vachlepi dan Suwardin (2015), bahan pengisi (filler) adalah bahan pendukung dengan porsi terbesar dalam pembuatan karet yang pemakaiannya ditujukan untuk meningkatkan sifat fisik, memperbaiki karakteristik pengolahan dan mengurangi biaya.

Karet alam maupun sintetis memiliki kelebihan dan kekurangan yang mempengaruhi sifat fisis kompon karet yang dihasilkan. Ketahanan kompon karet tergantung dari bahan penyusunnya, baik karet alam maupun karet sintetis. Karet alam tidak tahan terhadap ozon dan panas, tetapi memiliki ketahanan kikis yang tinggi. Sedangkan karet sintetis tahan terhadap ozon, panas dan ketahanan retak. Material elastomer berbasis SBR memiliki ketahanan retak yang cukup baik, tahan air dan tahan terhadap cuaca (Hassan et al., 2012).

Dalam pembuatan kompon bantalan kaki untuk mebel perlu digunakan kombinasi karet alam dan karet sintetis, agar karet bantalan kaki memiliki properti seperti ketahanan kikis dan pampatan tetap yang baik, mengingat fungsi karet bantalan kaki pada mebel kursi maupun meja berperan penting dalam beberapa hal seperti menyerap getaran, mengurangi gesekan kaki mebel dengan lantai, dan menahan beban mebel.

\section{BAHAN DAN METODE}

\section{Bahan}

Bahan yang digunakan dalam penelitian ini terdiri dari bahan baku berupa $R S S$ dan SBR, serta bahan pembantu berupa carbon black, $\mathrm{ZnO}$, asam stearat, TMQ, kaolin, mineral oil, MBT, dan sulfur.

\section{Peralatan}

Alat yang digunakan adalah neraca analitis, open mill (two-roll mill) $L 140 \mathrm{~cm}$ $D 18 \mathrm{~cm}$, alat cetak, timbangan metler p120 kapasitas $1200 \mathrm{~g}$, alat press, pisau potong, gunting, dan peralatan uji.

\section{Metode Penelitian}

Penelitian dirancang dengan melakukan formulasi kompon bantalan kaki sebanyak 4 perlakuan dengan 3 kali pengulangan. Data hasil uji yang dihasilkan disajikan dalam nilai rata-rata pengujian. Variasi perlakuan dilakukan pada perbandingan penggunaan phr RSS dan SBR berturut-turut: (100:0); (70:30); (50:50); dan (30:70).

Pengujian terhadap kompon karet bantalan kaki adalah parameter kekerasan (hardness), Shore A (ASTM D 2240), tegangan putus (tensile strength), $\mathrm{kg} / \mathrm{cm}^{2}$ (ASTM D 412), perpanjangan putus (elongation at break), \% (ASTM D 412), ketahanan sobek (tear resistance), $\mathrm{kg} / \mathrm{cm}^{2}$ (ASTM D 624), tegangan tarik (modulus 100\%) (ASTM D 412), pampatan tetap $25 \%$ (compression set),\% dan ketahanan kikis (abrassion), $\mathrm{mm}^{3} / \mathrm{kgm}$.

Tabel 1. Formula kompon karet bantalan kaki untuk mebel

\begin{tabular}{lcccc}
\hline \multirow{2}{*}{ Bahan } & \multicolumn{4}{c}{ Formula (phr) } \\
\cline { 2 - 5 } & I & II & III & IV \\
\hline Karet Alam : RSS & 100 & 70 & 50 & 30 \\
Karet Sintetis: & - & 30 & 50 & 70 \\
SBR 1502 & & & 25 & 25 \\
Carbon black N330 & 25 & 25 & 25 & 3 \\
ZnO & 3 & 3 & 3 & 2 \\
Asam Stearat & 2 & 2 & 2 & 1 \\
TMQ & 1 & 1 & 1 & 20 \\
Kaolin & 20 & 20 & 20 & 5 \\
Mineral Oil & 5 & 5 & 5 & 5 \\
MBT & 1 & 1 & 1 & 1 \\
Sulfur & 2,5 & 2,5 & 2,5 & 2,5 \\
\hline
\end{tabular}

Tabel 2. Syarat mutu karet bantalan kaki (rubber step) sepeda motor SNI 06-7032-2004

\begin{tabular}{lcl}
\hline \multicolumn{1}{c}{ Uraian } & Satuan & Persyaratan \\
\hline Kekerasan & Shore A & Min. 65 \\
Tegangan putus & $\mathrm{kg} / \mathrm{cm}^{2}$ & Min. 154 \\
$\begin{array}{l}\text { Perpanjangan putus } \\
\text { Ketahanan sobek }\end{array}$ & $\%$ Min. 350 \\
$\begin{array}{l}\text { Tegangan } \\
\text { (modulus 100\%) }\end{array}$ & $\mathrm{kg} / \mathrm{cm}^{2}$ & Min. 30 \\
$\begin{array}{l}\text { Pampatan Tetap 25\% } \\
\text { Ketahanan Kikis }\end{array}$ & $\%$ & Min. 25 \\
\hline
\end{tabular}




\section{Prosedur Penelitian}

Bahan untuk pembuatan kompon bantalan kaki mebel ditimbang dengan menggunakan neraca analitis dan beratnya disesuaikan dengan dengan formula pada Tabel 1. Sebagai tahap awal mastikasi, RSS digiling dengan menggunakan alat two-roll mill selama 2 menit hingga plastis, kemudian ditambahkan SBR hingga campuran menjadi homogen. Selanjutnya, dilakukan penambahan $\mathrm{ZnO}$ sebagai aktivator ke dalam gilingan karet sedikit demi sedikit, kemudian ditambahkan aktivator lainnya yaitu asam stearat, dan proses penggilingan tetap diteruskan. Sementara itu, dilakukan penambahan carbon black sebagai bahan pengisi penguat hingga terdispersi merata, kemudian ditambahkan bahan pengisi penambah volume yaitu kaolin. Sambil terus dilakukan penggilingan, tambahkan bahan pelunak mineral oil sedikit demi sedikit, bahan pencepat MBT, dan atioksidan TMQ. Terakhir dilakukan penambahan sulfur sambil terus dilakukan penggilingan terhadap kompon karet hingga homogen. Pembuatan kompon dilakukan dengan tiga kali ulangan untuk masingmasing formula, dan rata-rata hasil uji terlihat pada Tabel 3.

\section{HASIL DAN PEMBAHASAN}

Kompon karet bantalan kaki diuji untuk beberapa parameter sesuai dengan persyaratan SNI 06-7032-2004 karet bantalan kaki (rubber step) sepeda motor. Penggunaan standar ini dilakukan karena kondisi dan tipe penggunaan karet yang mempunyai kesamaan. Hasil pengujian kompon terdapat pada Tabel 3.

Berdasarkan Tabel 3, nilai kekerasan (hardness) kompon bantalan kaki memiliki kecenderungan (trend) meningkat dan mengalami stagnansi pada pemakaian kombinasi RSS:SBR sebesar 50:50. Kekerasan yang merupakan patokan ketahanan suatu bahan terhadap perubahan plastis lokal terlihat dari fenomena semakin kaku suatu vulkanisat kompon maka kekerasannya semakin tinggi. Kekerasan kompon karet berkaitan erat dengan elastisitasnya, karena jika karet semakin keras maka elastisitasnya akan berkurang atau semakin tidak elastis. Kekerasan sangat dipengaruhi oleh akibat penambahan bahan pengisi, dimana Liu et al. (2008) menyatakan bahwa optimasi panambahan bahan pengisi penguat mengakibatkan peningkatan nilai kekerasan. Selain itu, pengerasan vulkanisat karet berhubungan dengan berkurangnya densitas ikatan silang dalam matriks suatu polimer.

Tabel 3. Hasil uji mekanik fisik kompon karet bantalan kaki mebel

\begin{tabular}{|c|c|c|c|c|c|}
\hline \multirow[b]{2}{*}{ Uji Fisika } & \multicolumn{4}{|c|}{ Kompon } & \multirow{2}{*}{$\begin{array}{l}\text { Syarat } \\
\text { Mutu SNI } \\
06-7032- \\
2004 \\
\end{array}$} \\
\hline & I & II & III & IV & \\
\hline $\begin{array}{l}\text { Kekerasan, } \\
\text { Shore } A\end{array}$ & 60 & 64 & 68 & 68 & Min. 65 \\
\hline $\begin{array}{l}\text { Tegangan } \\
\text { Putus, } \mathrm{kg} / \mathrm{cm}^{2}\end{array}$ & 154 & 128 & 120 & 105 & Min. 154 \\
\hline $\begin{array}{l}\text { Perpanjangan } \\
\text { Putus, \% }\end{array}$ & 400 & 370 & 355 & 340 & Min. 350 \\
\hline $\begin{array}{l}\text { Ketahanan } \\
\text { Sobek, kg/ } \\
\mathrm{cm}^{2}\end{array}$ & 38 & 35 & 33 & 27 & Min. 30 \\
\hline $\begin{array}{l}\text { Tegangan } \\
\text { tarik (Modulus } \\
100 \% \text { ) }\end{array}$ & 28 & 26 & 25 & 24 & Min. 25 \\
\hline $\begin{array}{l}\text { Pampatan } \\
\text { Tetap, \% }\end{array}$ & 30 & 24 & 23 & 22 & Maks. 25 \\
\hline $\begin{array}{l}\text { Ketahanan } \\
\text { Kikis, DIN }\end{array}$ & 1,8 & 2,1 & 2,4 & 2,8 & Maks. 2 \\
\hline
\end{tabular}

Tegangan putus kompon karet bantalan kaki pada Tabel 3 mengalami penurunan seiring dengan penambahan karet sintetis SBR. Tegangan putus tertinggi yaitu 154 $\mathrm{kg} / \mathrm{cm}^{2}$ diperoleh pada penggunaan karet alam tanpa penambahan karet sintetis. Densitas sambung silang dan densitas cross linking dalam metriks polimer sangat berhubungan erat dengan tegangan putus (Ismail et al., 2005), dimana penurunan ikatan sambung silang dan daya ikat antar matriks pengisi dan polimer dapat terjadi akibat penurunan jumlah bahan pengisi yaitu carbon black (Kanking et al., 2012).

Perubahan struktur ikatan silang karet dapat dipengaruhi oleh kadar karbon dan silika bahan pengisi kompon. Kahar (2003) menyatakan bahwa kadar karbon dan silika 
yang berasal dari tempurung kelapa mampu merubah struktur ikatan silang dari karet. Dalam penelitian ini, tidak dilakukan variasi bahan pengisi sehingga penurunan tegangan putus disebabkan semakin meningkatnya komposisi bahan pengisi karet sintetis (SBR) dalam kompon.

Hasil uji tegangan putus karet bantalan kaki berbanding terbalik dengan nilai kekerasan. Ikatan silang dalam matriks polimer yang menyebabkan pengerasan vulkanisat yang berakibat pada menurunnya tegangan putus dapat dihubungkan dengan penambahan phr SBR yang semakin meningkat dimulai dari kompon II hingga kompon IV, namun tidak diiringi dengan peningkatan phr bahan pengisi penguat (carbon black) yang ditetapkan sebanyak 25 phr. Penggunaan SBR dalam pembuatan kompon karet perlu ditunjang dengan penambahan bahan pengisi. Bahan pengisi penguat perlu digabungkan untuk memperkuat karet yang tidak mengkristal seperti SBR, dan agar penguatan terjadi secara signifikan maka bahan pengisi harus berukuran kecil yaitu kurang dari $1 \mu \mathrm{m}$ (Hamed, 1992).

Perpanjangan putus (\%) kompon karet footspot menunjukkan pola penurunan yang sama dengan tegangan putus. Kompon dengan formula yang menggunakan karet alam 100 phr memiliki nilai kekerasan $400 \%$. Perpanjangan putus menurun seiring dengan penambahan karet SBR sebanyak 30, 50, dan 70 phr. Perpanjangan putus untuk kompon IV sebesar 340\% belum memenuhi standar perpanjangan putus dalam SNI 06-7032-2004.

RSS yang merupakan karet alam memiliki sifat elastisitas yang memungkinkan bagi karet untuk meregang dan kembali seperti semula. Pada saat proses vulkanisasi, karet alam bereaksi dengan bahan pemvulkanisasi, bahan pencepat, dan bahan penggiat membentuk ikatan silang dengan struktur jaringan tiga dimensi (Nasruddin, 2017).

Penggunaan bahan pengisi carbon black dengan kaolin juga mempengaruhi performa perpanjangan putus. Bahan pengisi penambah volume yang berlebihan dapat mengakibatkan penurunan nilai perpanjangan putus, sebaliknya bahan pengisi penguat apabila penggunaannya dalam rasio optimal dapat meningkatkan perpanjangan putus (Nasruddin, 2017). Bahan pengisi penguat mempengaruhi nilai tegangan putus dan perpanjangan putus kompon karet. Hassan et al. (2012) menyatakan bahwa bahan pengisi meningkatkan tegangan putus, perpanjangan putus, dan modulus Young yang mencerminkan efek penguat dari bahan pengisi, hal ini ditandai dengan kekakuan/kekerasan pada karet yang diisi dengan super abrasion furnace black filler (SAF) dan silika.

Penggunaan bahan pengisi penguat (carbon black) dan bahan pengisi penambah volume (kaolin) dalam penelitian ini dengan rasio $25 \mathrm{phr}$ : 20 phr. Jumlah bahan pengisi penambah volume yang hampir seimbang dengan bahan pengisi penguat diduga sebagai penyebab menurunnya perpanjangan putus kompon, dikombinasikan dengan penambahan SBR. Sommer (2009) menyatakan bahwa terdapat batasan yang memperbolehkan penambahan bahan pengisi, karena penambahan bahan pengisi mempengaruhi karakteristik pemrosesan dan juga sifat senyawa yang saling terkait.

Kompon karet bantalan kaki dapat mengalami kesobekan akibat pergesekan kompon dengan lantai maupun benda lain lainnya. Standar SNI 06-7032-2004 mempersyaratkan nilai ketahanan sobek kompon sebesar minimal $30 \mathrm{~kg} / \mathrm{cm}^{2}$. Ketahanan sobek karet bantalan kaki mebel tertinggi diperoleh pada penggunaan karet RSS sebanyak 100 phr dengan nilai 38 $\mathrm{kg} / \mathrm{cm}^{2}$. Sebaliknya dengan penambahan karet sintetis SBR maka ketahanan sobek menurun dengan nilai terkecil $\left(27 \mathrm{~kg} / \mathrm{cm}^{2}\right)$ terdapat pada kompon IV dengan penggunaan kombinasi phr RSS:SBR sebesar 30:70. Hal ini disebabkan oleh kemampuan karet sintetis yang memang tidak sebaik kemampuan karet alam dalam hal ketahanan sobek.

Menurut Thomas (2003), peningkatan ketahanan sobek dapat terjadi bila terdapat 
penambahan ikatan silang yang bermuara pada tingkat kerapatan tertentu. Menurut Kanking et al. (2012), ikatan sambung silang serta daya ikat antar matriks pengisi dan polimer dapat ditingkatkan dengan adanya penambahan jumlah bahan pengisi penguat carbon black. Kombinasi penggunaaan carbon black yang hampir seimbang dengan bahan pengisi penambah volume (kaolin) dalam penelitian ini, lalu dikombinasi dengan penambahan karet sintetis mengakibatkan ikatan sambung silang menjadi menurun. Besar nilai ketahanan sobek menandakan tingginya energi pemutusan polimer, hal ini dikarenakan optimalnya densitas ikatan silang dan tingkat kerapatan polimer dan bahan pengisi (Fang et al., 2014).

Hasil pengujian tegangan tarik menunjukkan pola menurun dari formula I hingga formula IV. Kompon yang tidak memenuhi syarat mutu untuk parameter tegangan putus adalah kompon IV dengan nilai $24 \%$. Tegangan tarik dipengaruhi oleh penggunaan bahan pelunak dan bahan pengisi. Perbaikan sifat (properties) dari komposit SBR yang mengandung partikel berukuran kecil dapat dihubungkan dengan dispersi yang lebih baik dari bahan pengisi yaitu SAF maupun silika (Blow, 1971). Interaksi yang kuat antara karet dengan bahan pengisi juga menyebabkan peningkatan sifat mekanik (Hassan et al., 2012). Jumlah bahan pengisi dan bahan pelunak yang digunakan dalam kompon karet sangat mempengaruhi nilai tegangan putus (Rahmaniar dan Nuyah, 2016).

Menurut Sommer (2009), bahan pengisi dengan ukuran partikel yang kecil memiliki luas permukaan yang besar berinteraksi dengan SBR dan meningkatkan kekuatannya lebih dari 10 kali lipat. Penambahan bahan pengisi dalam kompon karet memunculkan peningkatan linear dalam kekerasan bahan, lebih dari itu tingkat kekerasan karet berhubungan dengan elastisitas modulus (Rios et al., (2001); Manal U dan Aggarwal (2001)). Struktur dan ukuran bahan pengisi yang terdispersi dengan baik dalam matriks karet merupakan faktor utama yang menentukan peningkatan mechanical properties (Hassan et al., 2012).

Kompon yang mengandung karet alam lebih banyak memiliki nilai pampatan tetap yang lebih tinggi (Pal et al., 2010). Hasil penelitian Pal et al. (2010) menunjukkan nilai pampatan tetap yang lebih rendah dengan adanya penggabungan carbon black dengan tipe intermediate super abrasion furnace (ISF N234) yang strukturnya tinggi di alam. Hal ini mungkin disebabkan oleh peningkatan pembentukan rantai jaringan yang efektif karena efisiensi penguatan yang lebih tinggi dari high styrene rubber (HSR) dan silika nano dalam matriks karet (Hao et. al, 2001), dan juga efek plasticizing dari surfaktan organik (Zou et al. (2006); Xie et al. (2003)).

Ketahanan kikis merupakan sifat yang penting dimiliki oleh produk karet. Jika ketahanan kikis rendah maka produk yang dihasilkan akan mudah aus dan menyebabkan terjadinya kerusakan. Ketahanan kikis makin tinggi berarti karet makin tahan terhadap gesekan, namun mudah menjadi aus. Pada Tabel 3 , hasil pengujian ketahanan kikis tertinggi sebesar $2,8 \mathrm{~mm}^{3} / \mathrm{kgm}$ pada penggunaan rasio $\mathrm{phr}$ RSS:SBR sebesar 30:70. Penggunaan RSS sebesar 100 phr tanpa SBR menghasilkan nilai ketahanan kikis kompon yang terkecil yaitu $1,8 \mathrm{~mm}^{3} / \mathrm{kgm}$. Hal ini dapat dikatakan bahwa semakin banyak penggunaan SBR maka ketahanan kikis kompon semakin meningkat.

Apabila ketahanan sobek menunjukkan energi pemutusan, maka ketahanan kikis/abrasi menunjukkan pengikisan oleh benda tertentu akibat gesekan. Selain dipengaruhi oleh densitas ikatan silang, dispersi bahan pengisi dalam matriks polimer karet keberadaan anti oksidan untuk memperlambat pengusangan akibat gesekan perlu diperhatikan untuk memperkirakan ketahanan kikis produk karet. Nilai pengikisan akan sebanding dengan nilai kekerasan dan berat jenis vulkanisat karetnya (Susanto, 2016).

Pada penelitian ini, rata-rata nilai ketahanan kikis meningkat seiring dengan peningkatan rasio penggunaan SBR dalam 
formula kompon. Nilai ketahanan terkecil terdapat pada kompon I tanpa penggunaan SBR, yaitu $1,8 \mathrm{~mm}^{3} / \mathrm{kgm}$, dan meningkat meningkat menjadi lebih dari $2 \mathrm{~mm}^{3} / \mathrm{kgm}$ sejak adanya penggunaan SBR lebih dari 30 phr dalam formula I dan seterusnya. Hassan et al. (2012) mengatakan bahwa ketahanan kikis meningkat seiring dengan peningkatan SAF/SBR dengan kandungan di atas 30 phr. SAF merupakan carbon black tipe super abrasion furnace yang merupakan bahan pengisi penguat. Penelitian ini menggunakan carbon black sebagai bahan pengisi penguat sebanyak 25 phr $(<30$ phr $)$ dalam jumlah yang konstan untuk semua formula kompon, maka dapat disimpulkan bahwa yang berpengaruh besar terhadap kenaikan nilai ketahanan kikis kompon karet adalah SBR dengan komposisi lebih dari 30 phr.

Karet alam dan karet sintetis seperti polyisoprene (IR) memiliki pengatur regangan (strain-crystallizing) yang memberikan ketahanan yang baik, dan keduanya sangat kuat meskipun tanpa penambahan bahan pengisi, karena kristalit yang terbentuk di dalamnya dapat menghambat keretakan, dan ketahanan minimum bagi karet alam selama siklus regangannya secara signifikan mempengaruhi masa jenuhnya (Lake and Lindley, 1966).

Pemenuhan SNI 06-7032-2004 untuk ketahanan kikis terdapat pada kompon formula I yang tidak ada penambahan SBR. Jika seluruh hasil uji fisik mekanik terhadap keseluruhan kompon karet bantalan kaki, keunggulan kompon I terdapat pada parameter uji tegangan putus dan ketahanan kikis, namun ada yang belum memenuhi standar yaitu kekerasan 60 Shore A (standar minimal 65 Shore A) dan pampatan tetap 30\% (standar maksimal 25\%). Sedangkan kompon III memiliki keunggulan pada hasil uji kekerasan dan pampatan tetap, berturut-turut sebesar 68 Shore A dan $23 \%$. Menimbang beban kerja bantalan kaki sebagai bantalan meubel yang statis dan cenderung pada kemampuannya menahan beban, maka kompon yang memenuhi standar kekerasan dan pampatan tetap lebih diutamakan daripada ketahanan kikis.

\section{KESIMPULAN}

Berdasarkan hasil uji sifat mekanik fisik vulkanisat karet menggunakan kombinasi RSS dan SBR, hasil uji kompon yang terbaik terdapat pada kompon formula III, dengan karet alam RSS yang digunakan sebanyak 50 phr, dan SBR sebanyak 50 phr. Hasil pengujian menunjukkan bahwa hasil uji kekerasan sebesar 68 Shore $A$, tegangan putus $120 \mathrm{~kg} / \mathrm{cm}^{2}$, perpanjangan putus $355 \%$, tegangan tarik $100 \%$ yaitu 25 $\mathrm{kg} / \mathrm{cm}^{2}$, ketahanan sobek $33 \mathrm{~kg} / \mathrm{cm}^{2}$, ketahanan kikis $2,4 \mathrm{~mm}^{3} / \mathrm{kgm}$, dan pampatan tetap $25 \%$ sebesar $23 \%$.

\section{SARAN}

Penggunaan SBR dalam pembuatan kompon karet perlu ditunjang dengan penambahan bahan pengisi penguat untuk memperkuat karet SBR, dan perlu dilakukan penelitian lebih lanjut tentang pembuatan produk karet yang menggunakan kombinasi karet alam dengan SBR dan IR dan berbahan pengisi berukuran kecil (kurang dari $1 \mu \mathrm{m}$ ).

\section{UCAPAN TERIMA KASIH}

Terima kasih kepada Ir. Haryadi B selaku tenaga ahli dalam tim penelitian.dan reviewer Jurnal Dinamika Penelitian Industri Baristand Industri Palembang atas diskusi yang dilakukan dan masukan yang telah diberikan selama proses penyempurnaan tulisan ini.

\section{DAFTAR PUSTAKA}

Blow, C. M. (1971). Rubber technology and manufacture. Loughborough, Butterworths: London: University of Technology.

Fang, Y., M. Zhan, and Wang, Y. (2001). The status of recycling of waste rubber. Materials \& Design 22 (2):123-128.

Hamed, G. R. (1992). in Engineering with Rubber, A. N. Gent (Ed.), Hanser, 1st edition. p. 22 
Hassan, H. H., Ateia, E., Darwish, N. a., Halim, S. F., \& Abd El-Aziz, a. K. (2012). Effect of filler concentration on the physicomechanical properties of super abrasion furnace black and silica loaded styrene butadiene rubber. Materials and Design, 34 , 533-540. http://doi.org/10.1016/j.matdes.2011.05.00 5

Hao P.T., Ismail H., Hashim A.S. (2001) Study of two types of styrene butadiene rubber in tire tread compounds. Polym Test: 20(5):539-44.

Ismail, H., A. Rusli, and Rashid, A. (2005). Maleated natural rubber as a coupling agent for paper sludge filled natural rubber composites. Polymer Testing, 24(7):856-862.

Kahar, N. 2003. Rapat Ikatan Silang pada Karet Alam yang Divulkanisir. Teknologi Indonesia Jilid VIII. No. 2.

Kanking, S., Niltui, P., Wimolmala, E., and Sombatsompop, N. (2012). Use of bagasse fiber ash as secondary filler in silica on carbon black filled natural rubber compound. Materials Design, 41:74-82.

Lake, G. J. and Lindley, P. B. (1996). in Use of Rubber in Engineering, MacLaren and Sons Ltd., London. p. 67

Liu, C., Shao, Y. and Jia D. (2008). Chemical modified starch reinforced natural rubber composites., 49(8): 2176-2181.

Manal U, Aggarwal K (2001). Studies on rubber-filler interaction in carboxylated nitrile rubber through microhardness measurement. Polym Test; 20(3):305-11.

Nasruddin (2017). Karakteristik Sifat Mekanik Solid Tyre dengan Bahan Pengisi dan Pelunak Berbasis Sumber Daya Alam Lokal. Jurnal Dinamika Penelitian Industri, 28(1).

Pal, K., Rajasekar, R., Kang, D. J., Zhang, Z. X., Pal, S. K., Das, C. K., \& Kim, J. K. (2010). Effect of fillers on natural rubber/high styrene rubber blends with nano silica: Morphology and wear. Materials and Design, 31(2), 677-686. http://doi.org/10.1016/j.matdes.2009.08.01 4

Rahmaniar dan Nuyah. (2016). Pemanfaatan pasir kuarsa sebagai bahan pengisi dalam pembuatan karpet karet. Jurnal Dinamika Penelitian Industri, 27(2).

Rios S, Chicurel R, Del Castillo LF (2001). Potential of particle and fibre reinforcement of tyre tread elasttomers. Mater Des; 22(5):369-72.

Sommer, J. G. (2009). Engineered Rubber Products. Engineered Rubber Products: Introduction to Design, Manufacture and Testing. Munich: Hanser. http://doi.org/10.3139/9783446433441.fm

Susanto, T. (2016). Perbandingan sifat mekanik-fisik vulkanisat SBR dan SBR/NR menggunakan bahan pengisi pati termodifikasi resorcinol formaldehyde. Jurnal Dinamika Penelitian Industri 27(1).

Thomas, J. 2003. Disain kompon. Modul Pelatihan. Balai Penelitian Teknologi Karet Bogor.

Vachlepi, A. dan Suwardin, D. (2015). Kajian Pembuatan Kompon Karet Alam dari Bahan Pengisi Abu Briket Batubara dan Arang Cangkang Sawit. Jurnal Dinamika Penelitian Industri, 26(1).

White, J., \& Naskar, K. (2009). Rubber Technologist's Handbook. (J. White, S. K. De, \& K. Naskar, Eds.) (Vol. 2). United Kingdom: iSmithers Rapra.

Xie W, Hwu JM, Jiang GJ, Buthelezi TM, Pan WP. (2003). A study of the effect of surfactants on the properties of polystyrene - Polymer montmorillonite nanocomposites. Polym Eng Sci, 43:214-22.

Zou H, Xu W, Zhang Q, Fu Q. (2006). Effect of alkylammonium salt on the dispersion and properties of poly(p-phenylene sulfide)/clay nanocomposites via melt intercalation. $J$ Appl Polym Sci, 99:1724-31. 